\title{
Assessment of Antimicrobial Efficacy of Zinc Oxide Nanoparticles Synthesized Using Clove and Cinnamon Formulation against Oral Pathogens - An In Vitro Study
}

\author{
Subhashree Mohapatra ${ }^{1}$, Leelavathi L. ${ }^{2}$, Meignana Arumugham I. ${ }^{3}$, Pradeep Kumar R.. ${ }^{4}$, Rajeshkumar S. ${ }^{5}$ \\ ${ }^{1}$ Department of Public Health Dentistry, Saveetha Dental College, Saveetha Institute of Medial and Technical \\ Sciences, Chennai, Tamilnadu, India. ${ }^{2}$ Department of Public Health Dentistry, Saveetha Dental College, \\ Saveetha Institute of Medial and Technical Sciences, Chennai, Tamilnadu, India. ${ }^{3}$ Department of Public \\ Health Dentistry, Saveetha Dental College, Saveetha Institute of Medial and Technical Sciences, Chennai, \\ Tamilnadu, India. ${ }^{4}$ Department of Public Health Dentistry, Saveetha Dental College, Saveetha Institute of \\ Medial and Technical Sciences, Chennai, Tamilnadu, India. ${ }^{5}$ Department of Pharmacology, Saveetha Dental \\ College, Saveetha Institute of Medial and Technical Sciences, Chennai, Tamilnadu, India.
}

\section{ABSTRACT}

\section{BACKGROUND}

Zinc Oxide nanoparticle is of particular interest among researchers due to its wide range of applications. Green synthesis of nanoparticles has many benefits like being eco-friendly, less time consuming, cost effective, stable operation, and more importantly the process can be carried out without the involvement of any hazardous chemicals. Clove and cinnamon are known to have antimicrobial activity. Hence, this study was conducted to assess the antimicrobial efficacy of zinc oxide nanoparticles reinforced with clove and cinnamon against oral pathogens.

\section{METHODS}

This is an in vitro study. The organisms used were Streptococcus mutans, Staphylococcus aureus and Enterococcus faecalis. These bacteria were inoculated in their respective medium and incubated overnight. Agar well diffusion method was used to assess the antimicrobial efficacy of the nanoparticles at $25 \mu \mathrm{L}, 50 \mu \mathrm{L}$ and 100 $\mu \mathrm{L}$.

\section{RESULTS}

Zone of inhibition was found to be highest at $100 \mu \mathrm{L}$ against Streptococcus mutans, Staphylococcus aureus, and Enterococcus faecalis $(15 \mathrm{~mm}, 13 \mathrm{~mm}$, and $13 \mathrm{~mm}$ respectively).

\section{CONCLUSIONS}

Findings from this study suggest that zinc oxide nanoparticles reinforced with clove and cinnamon extracts has the potential as an antimicrobial agent against Streptococcus mutans, Staphylococcus aureus and Enterococcus faecalis and can be used as an alternative to commercially available antimicrobial agents.

\section{KEY WORDS}

Zinc Oxide Nanoparticles, Clove, Cinnamon, Anti-Microbial, Oral Pathogens
Corresponding Author:

Leelavathi L.,

Department of Public Health Dentistry,

Saveetha Dental College,

Saveetha Institute of Medical and Technical

Sciences, Chennai, Tamilnadu, India.

E-mail: karleela81@gmail.com

DOI: $10.14260 / \mathrm{jemds} / 2020 / 443$

How to Cite This Article:

Mohapatra S, Leelavathi L, Arumugham MI, et al. Assessment of antimicrobial efficacy of zinc oxide nanoparticles synthesized using clove and cinnamon formulation against oral pathogens-an in vitro study. J. Evolution Med. Dent. Sci. 2020;9(29):20342039, DOI: 10.14260/jemds/2020/443

Submission 27-02-2020,

Peer Review 08-06-2020,

Acceptance 16-06-2020,

Published 20-07-2020.

Copyright (c) 2020 JEMDS. This is an open access article distributed under Creative Commons Attribution License [Attribution 4.0 International (CC BY 4.0)] 


\section{BACKGROUND}

There has been a rapid evolution of nanoparticle synthesis recently as compared to the early part of the century.[1] Earlier, physio-chemical methods were involved in nanoparticle synthesis. Even though less time is utilized for synthesizing large quantities of nanoparticles using conventional physical and chemical methods, toxic chemicals are required as capping agents to maintain stability, thus leading to toxicity in the environment.[2] Keeping this in consideration, green nanotechnology using plants is emerging as an eco-friendly alternative, as plant extract mediated biosynthesis of nanoparticles is cost-effective. [2] The high surface area to volume ratio of nanoparticle is a notable distinctive feature which enables excellent molecular interaction characteristics with its smaller size, distribution and morphology.[3] Green synthesis of nanoparticles has many benefits like eco-friendly, less time consuming, cost effective, stable operation and more importantly the process can be carried out without the involvement of any hazardous chemicals. ${ }^{44-6]}$

Among the various inorganic nanoparticles available, Zinc Oxide ( $\mathrm{ZnO}$ ) has easy processing methods, is inexpensive, has wide range of applications and is a safe material. Due to these properties, Zinc Oxide pulls a particular interest among researchers. Zinc Oxide plays a vital role in the daily life and has the third highest global production volume only after Selenium Oxide $\left(\mathrm{SiO}_{2}\right)$ and Titanium Oxide $\left(\mathrm{TiO}_{2}\right)$ among the safest metal to use [7,8]. Recent studies have shown that Zinc Oxide nanoparticles are potentially toxic to bacteria but exhibit minimal effects on human cells.[9,10] The biocompatibility of the Zinc Oxide nanoparticles is due to its particle size and shape, aspect ratio and morphology.[11]

Zinc Oxide nanoparticles are eco-friendly and have biodegradability properties. Zinc Oxide nanoparticles have a large surface volume ratio which facilitates better dissolution and penetration of the bacteria,[12,13] thus having prominent antimicrobial activities. Zinc Oxide nanoparticles antibacterial efficiency is mainly from the nanoparticles as compared to the release of free $\mathrm{Zn}{ }^{2+}$ ions which is very low.[14] The antimicrobial property of Zinc Oxide nanoparticles has been proved in many studies.[15-17]

Syzygium aromaticum commonly known as clove, is a median size tree (8-12 $\mathrm{m}$ ) belonging to the Mirtaceae family native of Maluku islands in east Indonesia.[18] For many years the trade of clove has caused the economic development of this region.[18]-Eugenol is the main bioactive compound of clove, which is found in concentrations ranging from 9381.70 to 14 $650.00 \mathrm{mg}$ per $100 \mathrm{~g}$ of fresh plant material.[19] The antimicrobial activities of clove have been proved against several bacterial and fungal strains.[20,21] Sofia et al. tested the antimicrobial activity of different Indian spice plants as mint, cinnamon, mustard, ginger, garlic and clove.[22] The only sampled that showed complete bactericidal effect against all the pathogens tested Escherichia coli, Staphylococcus aureus and Bacillus cereus was the aqueous extract of clove at $3 \%$. At the concentration of $1 \%$ clove extract also showed good inhibitory action.

Cinnamon is a spice obtained from the inner bark of several tree species from the genus Cinnamomum [23]. Cinnamon has many health benefits like-it is loaded with antioxidant, has inti-inflammatory properties, may reduce the risk of heart disease, lowers blood sugar level, protective against cancer, and anti-microbial properties. The antimicrobial activity of cinnamon is due to its constituentscinnamaldehyde (4.3\%) and eugenol $(0.32 \%) .{ }^{[23]}$

The rationale of this study is that no study has been conducted so far in which the antimicrobial properties of Zinc Oxide nanoparticles reinforced with clove and cinnamon have been assessed. Hence the aim of the study was to assess the antimicrobial efficacy of Zinc Oxide nanoparticles reinforced with clove and cinnamon against oral pathogens.

\section{METHODS}

\section{Study Design}

In vitro study.

\section{Study Organisms}

The test organisms used in this study were obtained from the Culture Collections of the Nanobiomedicine Laboratory, Saveetha Dental College, Chennai. The organisms used in this study were Streptococcus mutans, Staphylococcus aureus and Enterococcus faecalis.

\section{Preparation of Plant Extract}

Clove buds and cinnamon bark sticks were purchased from the market and were powdered using a mixer grinder. $500 \mathrm{mg}$ of clove powder and $500 \mathrm{mg}$ of cinnamon powder were dissolved in $100 \mathrm{~mL}$ of distilled water. The solution was boiled in a heating mantle at $60{ }^{\circ} \mathrm{C}$ for 10 minutes until the bubbles appeared. The solution was filtered using a funnel and a Whatman filter paper and collected in a conical flask to obtain the plant extract. Then the plant extract was transferred to an airtight container and refrigerated overnight.

\section{Synthesis of Zinc Oxide Nanoparticles Using Clove and Cinnamon Extract}

$20 \mathrm{mM}$ of Zinc Sulphate powder was prepared using $60 \mathrm{~mL}$ of distilled water and mixed thoroughly. $40 \mathrm{~mL}$ of the plant extract was added to this solution and was placed in the orbital shaker. Colour change of the solution was noted every $2 \mathrm{~h}$. Readings were recorded every $2 \mathrm{~h}$ in U V Spectrophotometer and after around $36 \mathrm{~h}$, centrifugation was done at $7000 \mathrm{rpm}$ for 10 minutes. Zinc Oxide nanoparticles pellets reinforced with clove and cinnamon were obtained after centrifugation.

\section{Antimicrobial Activity \\ Agar Well Diffusion Method was used to assess the antimicrobial efficacy.}

\section{Media Preparation}

$100 \mathrm{~mL}$ of Mueller Hinton agar for Streptococcus mutans, Staphylococcus aureus and Enterococcus faecalis and was prepared, sterilized and poured onto the Petri plates. The plates were allowed for solidification. 


\section{Swabbing}

After solidification, the respective plates was swabbed with the oral pathogens-Streptococcus mutans, Staphylococcus aureus and Enterococcus faecalis.

\section{Well Formation}

After swabbing, three wells on each plates were formed using a gel puncher. To those three wells, Zinc Oxide nanoparticle with clove and cinnamon solution was loaded in the concentration range of $25 \mu \mathrm{L}, 50 \mu \mathrm{L}$ and $100 \mu \mathrm{L}$. The plates were then incubated at $37^{\circ} \mathrm{C}$ for $24 \mathrm{hrs}$. and after incubation, the zone of inhibition was measured and calculated.

\section{Measurement of Zone of Inhibition}

The test plates were held in front of a desk lamp, and the zones were measured with a ruler held against the back of the petri plate. The diameters of the zones of inhibited growth were measured to the nearest whole millimeter.

\section{RESULTS}

Figure 1 depicts the antimicrobial activity of Zinc oxide nanoparticles reinforced with clove and cinnamon extract against Streptococcus mutans. Zone of inhibition was found to be highest at concentration of $100 \mu \mathrm{L}(15 \mathrm{~mm})$. Figure 2 depicts the antimicrobial activity of Zinc oxide nanoparticles reinforced with clove and cinnamon extract against Staphylococcus aureus. Zone of inhibition was found to be highest at concentration of $100 \mu \mathrm{L}(13 \mathrm{~mm})$. Figure 3 depicts the antimicrobial activity of Zinc oxide nanoparticles reinforced with clove and cinnamon extract against Enterococcus faecalis. Zone of inhibition was found to be highest at concentration of $100 \mu \mathrm{L}(13 \mathrm{~mm})$.
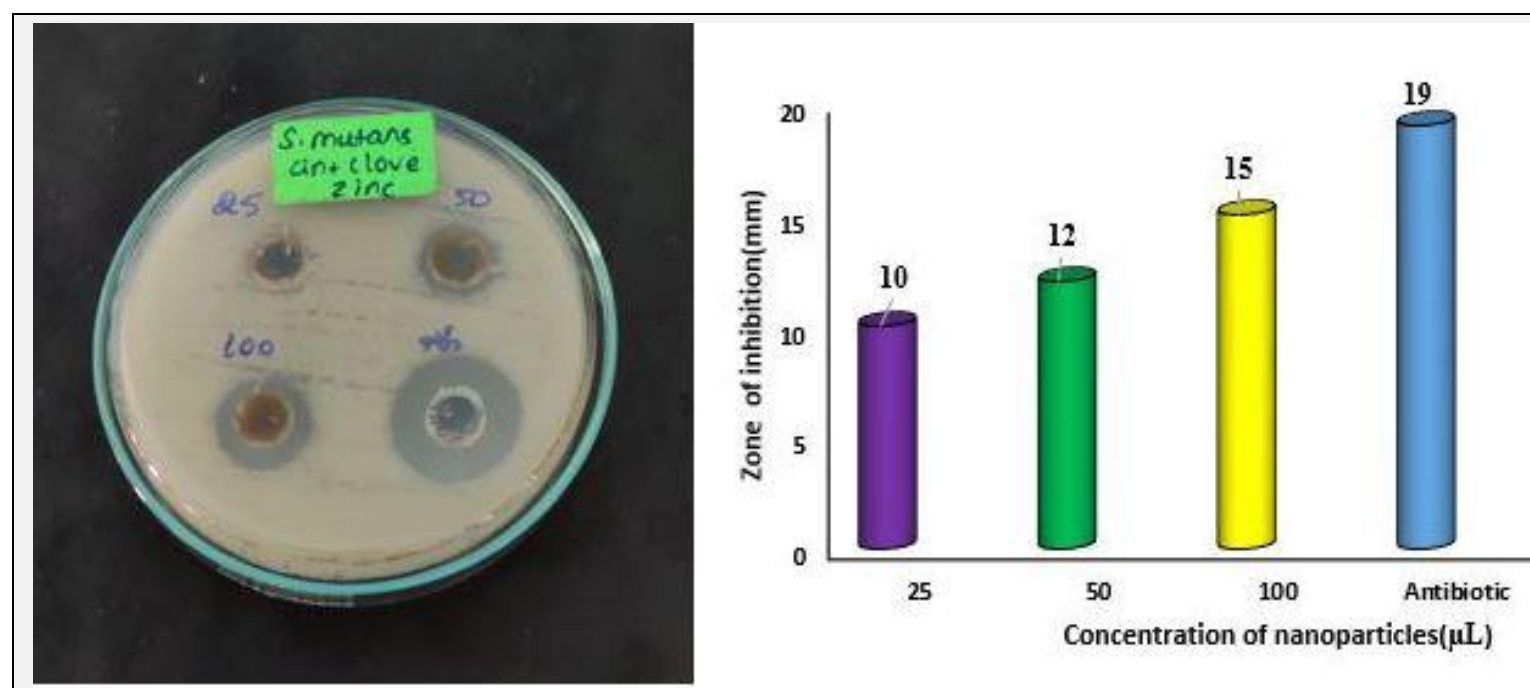

Figure 1. Antimicrobial Activity of Zinc Oxide Nanoparticles Reinforced with Clove and Cinnamon Extract against Streptococcus mutans
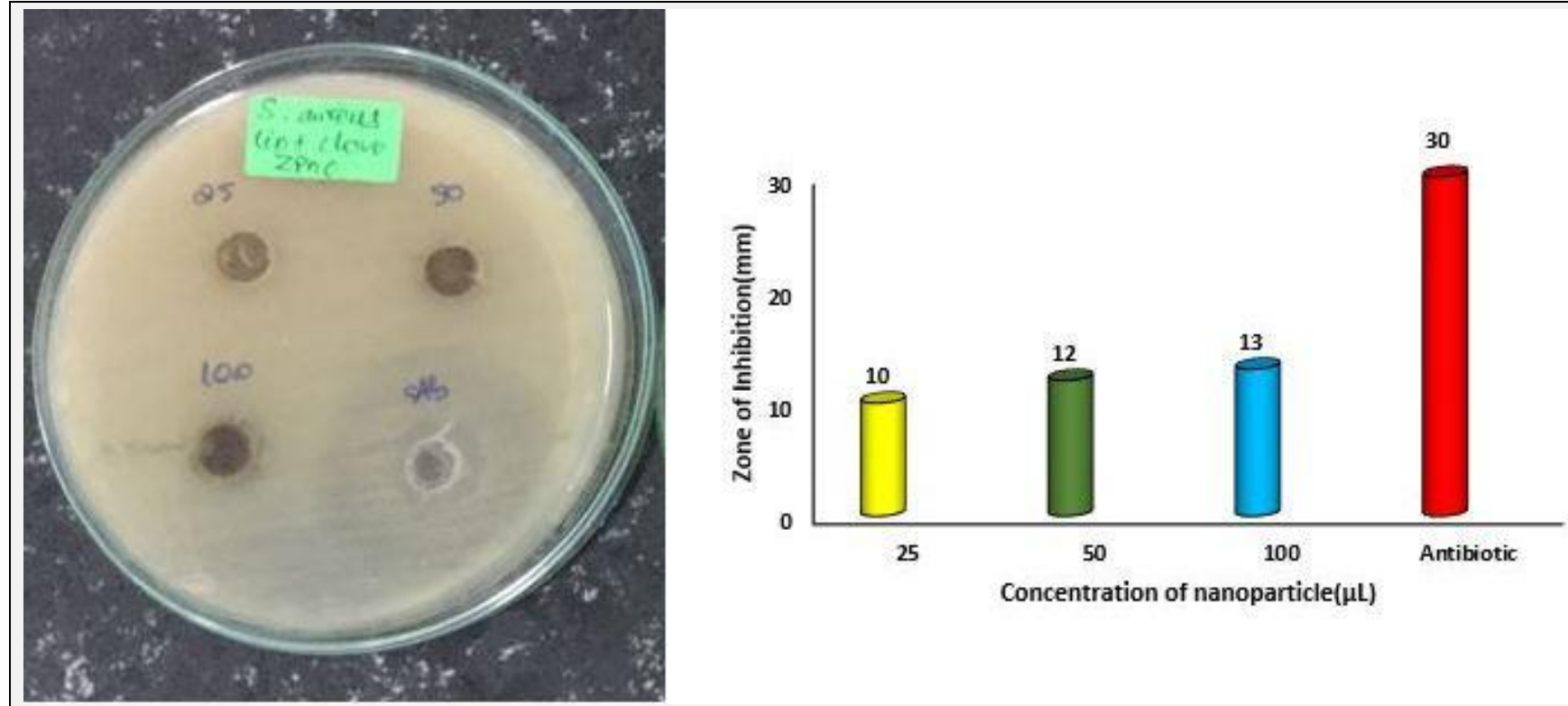

Figure 2. Antimicrobial Activity of Zinc Oxide Nanoparticles Reinforced with Clove and Cinnamon Extract against Staphylococcus aureus 

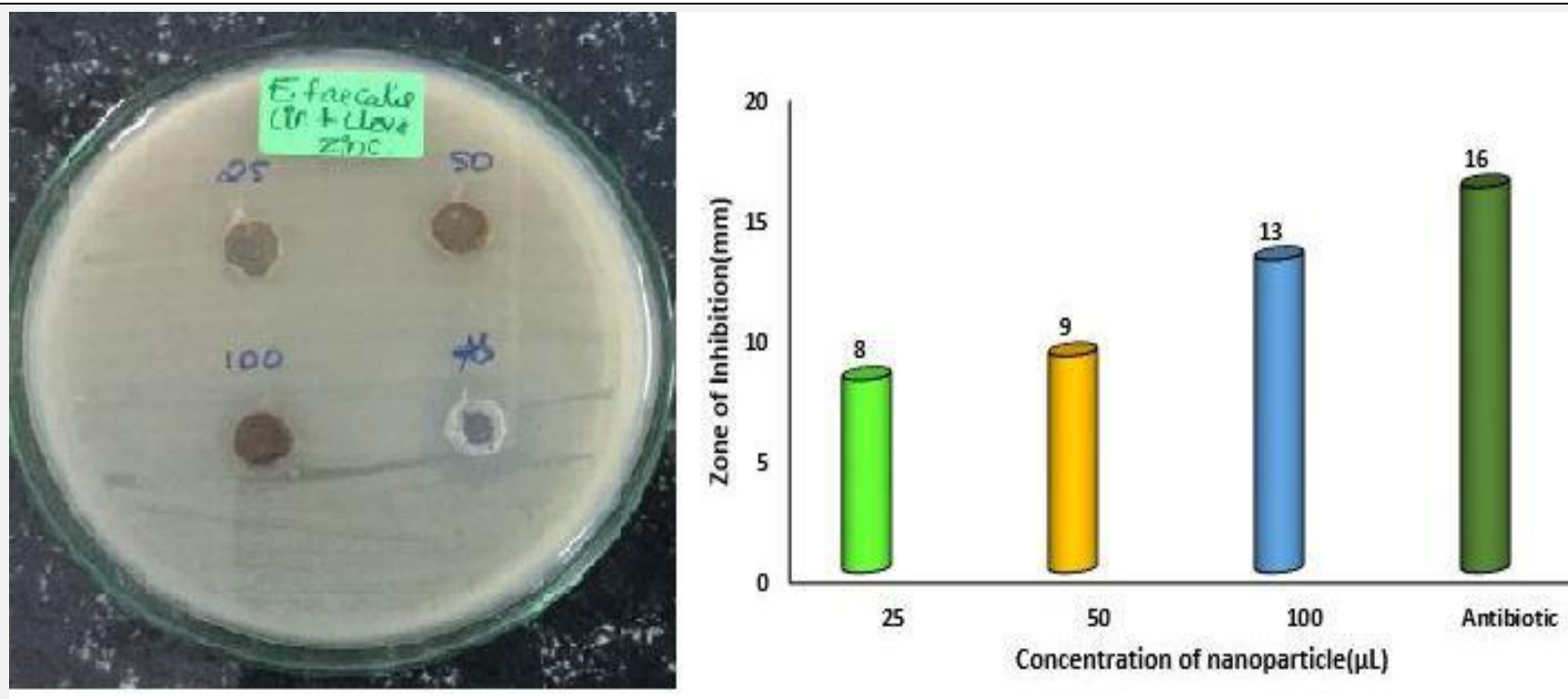

Figure 3. Antimicrobial Activity of Zinc Oxide Nanoparticles Reinforced with Clove and Cinnamon Extract against Enterococcus faecalis

\section{DISCUSSION}

Now microorganisms have become resistance to many antibiotics due to increased use of drugs, which is decreasing efficiency of conventional medicines. So, it has become necessary to find out new antimicrobial agents. Nanotechnology is an emerging technology and has led to a new revolution in every field of science. ${ }^{[24]}$ Among the various inorganic Nanoparticles available, Zinc Oxide has easy processing methods, is inexpensive, has wide range of applications in dentistry and is a safe material. Due to these properties, Zinc Oxide pulls a particular interest among researchers.

Green synthesis offers numerous benefits of eco friendliness and compatibility for biomedical applications, where toxic chemicals are not used for the synthesis protocol. The active ingredients of plants against microorganisms are mostly some of the secondary metabolites (i.e. alkaloids, glycosides etc.) that are present in abundance in herbs.

In this study the zone of inhibition against Streptococcus mutans at $25 \mu \mathrm{L}$ concentration was $10 \mathrm{~mm}$, at $50 \mu \mathrm{L}$ was 12 $\mathrm{mm}$ and at $100 \mu \mathrm{L}$ was $15 \mathrm{~mm}$. Zone of inhibition against Staphylococcus aureus at $25 \mu \mathrm{L}$ was $10 \mathrm{~mm}$, at $50 \mu \mathrm{L}$ was 12 $\mathrm{mm}$ and at $100 \mu \mathrm{L}$ was $13 \mathrm{~mm}$. Zone of inhibition against Enterococcus faecalis at $25 \mu \mathrm{L}$ was $8 \mathrm{~mm}, 50 \mu \mathrm{L}$ was $9 \mathrm{~mm}$ and at $100 \mu \mathrm{L}$ was $13 \mathrm{~mm}$. So, it was seen that as the concentration of the Zinc Oxide nanoparticles reinforced with clove and cinnamon extract increased, the antimicrobial activity increased. The anti-microbial activity against Enterococcus faecalis was found to less as to the other two bacteriae. The reason could be that Enterococcus faecalis is highly resistant to antimicrobial agents.

In Ayurveda clove has been used for its medicinal properties.[25] It has an anaesthetic effect which is effective numbing small regions like teeth. Thus, it has been used actively in dentistry. Also, since this is natural and so does not have any side effects.[26] Clove also contains in small quantities active anti-microbial tannins like gallotannic acid and methyl salicylate.

There are many studies done which have proved the antimicrobial activity of clove.[27-29] The main component of clove is eugenol which is responsible for the antimicrobial activity. It is well known that eugenol is a phenolic compound that can denature proteins and react with cell membrane phospholipids. This changes their permeability and inhibit Gram-negative and Gram-positive bacteria as well as different types of yeast [30]. It has also been found that addition of clove in combination with metal nanoparticles have enhanced antimicrobial activity. [31-33]

Antimicrobial activity of zinc nanoparticles by green synthesis using clove [34] and cinnamon have shown promising results.[35] The reason could be that zinc oxide nanoparticles disrupt bacterial cell membrane integrity, reduce cell surface hydrophobicity, and downregulate the transcription of oxidative stress-resistance genes in bacteria which leads to its lysis. [36]

Various biologically active compounds identified in cinnamon such as cinnamaldehyde, cinnamic acid, cinnamyl acetate, eugenol and others are responsible for its antimicrobial, antiulcer, antidiabetic, anti-inflammatory and antioxidant properties. Antimicrobial activity of cinnamon against oral pathogens has been proved in many studies.[37-40] Cinnamaldehyde is one of the main components of cinnamon that is responsible for the antimicrobial activity.

Based on the findings of the study we can say that zinc oxide nanoparticles reinforced with clove and cinnamon extract can be used as an alternative to commercially available antimicrobial agents.

\section{Limitation}

The study was conducted in vitro, so it cannot be assumed that the results of antimicrobial efficacy could be translated into clinical effectiveness. 


\section{Recommendations}

- $\quad$ This product can be given to the patients in the form of a mouthwash.

- In further studies, in vivo studies are recommended with people' acceptance values as well.

\section{CONCLUSIONS}

Findings from this study suggest that zinc oxide nanoparticles reinforced with clove and cinnamon extracts has the potential as an antimicrobial agent against Streptococcus mutans, Staphylococcus aureus and Enterococcus faecalis and can be used as an alternative to commercially available antimicrobial agents.

Authors thank Dr. S. Rajeshkumar, Department of Pharmacology, Saveetha Dental College for guiding us in the study.

\section{REFERENCES}

[1] Andersson M, Pedersen JS, Palmqvist AEC. Silver nanoparticle formation in microemulsions acting both as template and reducing agent. Langmuir 2005;21(24):11387-96.

[2] Chandran SP, Chaudhary M, Pasricha R, et al. Synthesis of gold nanotriangles and silver nanoparticles using aloe vera plant extract. Biotechnol Prog 2000;22(2):577-83.

[3] Vidya C, Hirematha S, Chandraprabhab MN, et al. Green synthesis of $\mathrm{ZnO}$ nanoparticles by calotropis gigantea. International Journal of Current Engineering and Technology 2013:118-20.

[4] Ahmed S, Ahmad SM, Swami BL, et al. Green synthesis of silver nanoparticles using Azadirachta indica aqueous leaf extract. Journal of Radiation Research and Applied Sciences 2016;9(1):1-7.

[5] Vijayaraghavan K, Kamala Nalini SP, Udaya Prakash N, et al. One step green synthesis of silver nano/microparticles using extracts of trachyspermum ammi and papaver somniferum. Colloids Surf B Biointerfaces 2012;94:114-7.

[6] Aruna A, Nandhini R, Karthikeyan V, et al. Synthesis and characterization of silver nanoparticles of insulin plant (costus pictus D. Don) leaves. Asian Journal of Biomedical and Pharmaceutical Sciences 2014;4(34):1-6.

[7] Piccinno F, Gottschalk F, Seeger S, et al. Industrial production quantities and uses of ten engineered nanomaterials in Europe and the world. J Nanopart Res 2012;14(9):1109.

[8] Raguvaran R, Manuja A, Manuja BK, et al. Sodium alginate and gum acacia hydrogels of zinc oxide nanoparticles reduce hemolytic and oxidative stress inflicted by zinc oxide nanoparticles on mammalian cells. Int J Biol Macromol 2017;101:967-72.

[9] Reddy KM, Feris K, Bell J, et al. Selective toxicity of zinc oxide nanoparticles to prokaryotic and eukaryotic systems. Appl Phys Lett 2007;90(213902):21390212139023.
[10] Chopra M, Bernela M, Kaur P, et al. Alginate/gum acacia bipolymeric nanohydrogels--promising carrier for Zinc oxide nanoparticles. Int J Biol Macromol 2015;72:827-33.

[11] Dakhlaoui A, Jendoubi M, Smiri LS, et al. Synthesis, characterization and optical properties of $\mathrm{ZnO}$ nanoparticles with controlled size and morphology. J Cryst Growth 2009;311(16):3989-96.

[12] Xie Y, He Y, Irwin PL, et al. Antibacterial activity and mechanism of action of zinc oxide nanoparticles against campylobacter jejuni. Appl Environ Microbiol 2011;77(7):2325-31.

[13] Bai X, Li L, Liu H, et al. Solvothermal synthesis of ZnO nanoparticles and anti-infection application in vivo. ACS Appl Mater Interf 2015;7(2):1308-17.

[14] Raghupathi KR, Koodali RT, Manna AC. Size-dependent bacterial growth inhibition and mechanism of antibacterial activity of zinc oxide nanoparticles. Langmuir 2011;27(7):4020-8.

[15] Emami-Karvani Z, Chehrazi P. Antibacterial activity of $\mathrm{ZnO}$ nanoparticle on grampositive and gram-negative bacteria. African Journal of Microbiology Research 2011;5(12):1368-73.

[16] Eshed M, Lellouche J, Matalon S, et al. Sonochemical coatings of $\mathrm{ZnO}$ and $\mathrm{CuO}$ nanoparticles inhibit Streptococcus mutans biofilm formation on teeth model. Langmuir 2012;28(33):12288-95.

[17] Gunalan S, Sivaraj R, Rajendran V. Green synthesized ZnO nanoparticles against bacterial and fungal pathogens. Progress in Natural Science: Materials International 2012;22(6):693-700.

[18] Kamatou GP, Vermaak I, Viljoen AM. Eugenol--from the remote Maluku Islands to the international market place: a review of a remarkable and versatile molecule. Molecules 2012;17(6):6953-81.

[19] Neveu V, Perez-Jiménez J, Vos F, et al. Phenol-explorer: an online comprehensive database on polyphenol contents in foods. Database (Oxford) 2010;2010:bap024.

[20] Thosar N, Basak S, Bahadure RN, et al. Antimicrobial efficacy of five essential oils against oral pathogens: an in vitro study. Eur J Dent 2013;7(Suppl 1):71-7.

[21] Sharma A, Sankhla B, Parkar SM, et al. Antimicrobial activity of clove and ginger powder extracts on Streptococcus mutans. Sch Acad J Biosci 2014;2(12B):9536.

[22] Sofia PK, Prasad R, Vijay VK, et al. Evaluation of antibacterial activity of Indian spices against common foodborne pathogens. Int J Food Sci Technol 2007;42(8):910-5.

[23] Naveed R, Hussain I, Tawab A, et al. Antimicrobial activity of the bioactive components of essential oils from Pakistani spices against salmonella and other multi drug reistant bacteria. BMC Complement Altern Med 2013;13:265.

[24] Rico CM, Majumdar S, Duarte-Gardea M, et al. Interaction of nanoparticles with edible plants and their possible implications in the food chain. J Agric Food Chem 2011;59(8):3485-98.

[25] Clove (Eugenia aromatica) and Clove oil (Eugenol). National Institutes of Health, Medicine Plus. nlm.nih.gov 2012. 
[26] Kurokawa M, Hozumi T, Basnet P, et al. Purification and characterization of eugeniin as an anti-herpesvirus compound from geum japonicum and Syzygium aromaticum. J Pharmacol Exp Ther 1998;284(2):728-35.

[27] Chawla T, Abbasi NI, Tandon A, et al. Antimicrobial activity of spices like cloves cardamom and cinnamon on bacillus and pseudomonas. International Journal of Drug Development \& Research 2014;6(4):112-8.

[28] Abdullah BH, Hatem SF, Jumaa W. A comparative study of the antibacterial activity of clove and rosemary essential oils on multidrug resistant bacteria. Pharmaceutical and Biosciences Journal 2015;3(1):18-22.

[29] Packyanathan JS, Prakasam G. Antibacterial effect of clove oil against clinical strains of escherichia coli. J Pharm Sci Res 2017;9(7):1203-4.

[30] Walsh SE, Maillard JY, Russell AD, et al. Activity and mechanisms of action of selected biocidal agents on grampositive and-negative bacteria. J Appl Microbiol 2003;94(2):240-7.

[31] Hamed SF, Sadek Z, Edris A. Antioxidant and antimicrobial activities of clove bud essential oil and eugenol nanoparticles in alcohol-free microemulsion. J Oleo Sci 2012;61(11):641-8.

[32] AbdEl-Aziz DM, Yousef NMH. Enhancement of antimicrobial effect of some spices extract by using biosynthesized silver nanoparticles. International Food Research Journal 2018;25(2):589-96.

[33] Kaur H, Kaur S, Singh M. Biosynthesis of silver nanoparticles by natural precursor from clove and their antimicrobial activity. Biologia 2013;68(6):1048-53.
[34] Javad S, Akhter I, Aslam K, et al. Antibacterial activity of plant extract and zinc nanoparticles obtained from Syzigium aromaticum L. Pure Appl Biol 2017;6(4):107987.

[35] Abdollahzadeh E, Hosseini HM, Fooladi AAI. Antibacterial activity of agar-based films containing nisin, cinnamon EO, and ZnO nanoparticles. Journal of Food Safety 2018;38(3):e12440.

[36] Pati R, Mehta RK, Mohanty S, et al. Topical application of zinc oxide nanoparticles reduces bacterial skin infection in mice and exhibits antibacterial activity by inducing oxidative stress response and cell membrane disintegration in macrophages. Nanomedicine 2014;10(6):1195-208.

[37] Prabuseenivasan S, Jayakumar M, Ignacimuthu S. In vitro antibacterial activity of some plant essential oils. BMC Complement Altern Med 2006;6:39.

[38] Aneja KR, Joshi R, Sharma C. Antimicrobial activity of Dalchini (Cinnamomum zeylanicum bark) extracts on some dental caries pathogens. Journal of Pharmacy Research 2009;2(9):1387-90.

[39] Zainal-Abidin Z, Mohd-Said S, Majid FAA, et al. Antibacterial activity of cinnamon oil on oral pathogens. The Open Conference Proceedings Journal 2013;4(Suppl 2):12-16.

[40] Waty S, Suryanto D, Yurnaliza. Antibacterial activity of cinnamon ethanol extract (cinnamomum burmannii) and its application as a mouthwash to inhibit Streptococcus growth. IOP Conf. Series: Earth and Environmental Science 2018;130(1):012049. 